\title{
EMG/NCV in the evaluation of spine trauma with radicular symptoms
}

Andrew J. Haig, MD, University of Michigan, Ann Arbor; John C. Kincaid, MD, Indiana University, Indianapolis; Timothy Dillingham, MD, MS, University of Pennsylvania, Philadelphia; Peter Grant, MD, private practice, Medford, OR: A recent article by Charles and Souayah ${ }^{1}$ concludes that electrodiagnostic testing for spinal disorders is of little value. As neurologists and physiatrist subspecialists in the field, we disagree. Much of the evidence presented is incorrect, incomplete, or outdated, leading to faulty conclusions. This short letter can only highlight a few problems. The authors claim that no practice guidelines are available when these are readily available from the American Association of Neuromuscular and Electrodiagnostic Medicine and others. ${ }^{2,3}$ The article cites early unmasked studies to claim that paraspinal EMG has such a high false-positive rate that it is useless. This contrasts with the modern literature. For example, a masked, double-controlled study using validated reproducible techniques and established norms found that abnormal paraspinal EMG was 100\% specific, in great contrast to the low specificity of diagnostic imaging. ${ }^{4}$ In addition to positively diagnosing spinal nerve disorders, EMG has also been shown in various situations to detect diseases that mimic spinal disorders, localize pathology for surgical and injection treatments, establish the duration of symptoms, establish the severity of disease, and predict or validate outcomes from certain spinal treatments. The literature, in contrast to this article, shows that electrodiagnosis is a useful and validated test for spinal disorders. A more detailed response can be found at www.aanem.org/defending-edx.

Disclosures: A. Haig has received funding for travel and speaker honoraria from academic organizations and universities; serves/has served on the editorial boards of PMß R, The Spine Journal, Journal of Back and Musculoskeletal Rehabilitation, Journal of Rehabilitation Medicine, and Portuguese Journal of Rehabilitation; is President of Haig et al consultants and has served as a consultant for Center for Health Care Research and Transformation, Jerudong Park Medical Centre, Brunei, and on occasional legal cases; performs electrodiagnostic clinical services and research at the University of Michigan; and has received funding from the NIH and the Center for Health Care Research and Transformation. T. Dillingham has received funding from the NIH. J. Kincaid performs EMG (50\% effort) as chief of the EMG laboratories at Indiana University and Indiana University Health. P. Grant reports no disclosures.

Correspondence to: andyhaig@umich.edu

Author Responds: James A. Charles, MD, FAAN, New Jersey Medical School, Newark: Our article ${ }^{1}$ did not conclude that electrodiagnostic testing for spinal disorders is of little value. We concluded that in a subset of patients with spinal trauma with radicular symptoms (STRS), there is limited evidence to support the use of EMG/nerve conduction studies (NCS). The American Association of Electrodiagnostic Medicine practice parameter for needle electromyographic evaluation of patients with suspected cervical radiculopathy was not a practice parameter offering guidelines for STRS. ${ }^{2}$ However, the article indicates that the sensitivity of needle EMG was $50 \%$ to $71 \%$, an issue we discussed in our article.

Cho et al. ${ }^{3}$ found that none of the reviewed studies addressed the utility of electrodiagnostic testing in prognosticating outcome or response to treatments. Again, there was no discussion of a subset of patients with STRS.

The masked, double-controlled study using validated reproducible techniques and established norms did indeed find that abnormal paraspinal EMG was 100\% specific. This study also found that abnormal paraspinal EMG was 30\% sensitive. ${ }^{4}$ We agree that EMG has also been shown in various situations to detect diseases that mimic spinal disorders. This is why we concluded that EMG/NCS in STRS are indicated when there is a differential diagnosis between a root lesion and a distal neuropathic/myopathic lesion. ${ }^{1}$ 
The reaction of Haig et al. to our review has led them to underquote the points of our article, thereby disingenuously recreating our review of the literature into conclusions that we did not make. Good medical practice in patients with spinal trauma with radicular symptoms begins with the history, physical examination, and appropriate imaging study. As neurologists and clinical neurophysiologists, we see countless requests for EMG/NCS in these cases. Our review of the literature focused only on the clinical subject of STRS. We concluded only in this subset of patients that EMG/NCS is indicated and appropriate when there is a differential diagnosis of a root vs a distal neuropathic lesion that cannot be resolved by history, physical examination, and imaging. In the other patients with STRS, after completing the clinical evaluation and integrated imaging, any additional information from EMG/NCS, including paraspinal mapping, will have limited practical clinical usefulness in diagnosis, treatment decision, and prognosis. Our review is relevant and timely to address the epidemic of electrodiagnostic fraud in a scholarly manner ${ }^{5}$ and to address uncomfortable and costly unnecessary electrodiagnostic studies. There are cases of STRS that are complex with so many comorbidities that clinical judgment may need bolstering by EMG/NCS. An honest clinician neurologist or physiatrist who is treating patients with STRS should not have fears that our conclusions will lower their income. Relevant studies discuss electrodiagnostic testing and methodology of nerve root function that complements information from history, examination, and imaging studies in patients with radiculopathy, and demonstrate variable sensitivities and specificities due to various timing, anatomical, and comorbidity reasons. However, there are no practice parameters or established guidelines on the clinical utility of EMG/NCS in the evaluation of STRS. Current practice can include a systematic referral to the electrodiagnostic laboratory seeking information about neurologic complaints from STRS, and for preoperative and postoperative diagnostic and prognostic evaluations. This review suggests that such referrals, without clinical or imaging correlates, can be of low yield, notwithstanding the expense and discomfort from testing. It appears that unless there is a clinical differential diagnosis including a peripheral neuropathic/myopathic lesion vs a root lesion that cannot be resolved with the history, neurologic examination, and imaging studies, there is limited evidence to support the use of EMG/NCS in the evaluation, treatment, and prognosis of patients with STRS. Most study sample sizes are small, nonrandomized, or inadequately powered to assess improved outcomes from EMG/NCS studies. Better evidence for utility of EMG/NCS in STRS is required in the form of randomized clinical trials or large-scale outcome studies. ${ }^{1}$

Disclosures: The author reports no disclosures.

Correspondence to: jacharlesmd@gmail.com

1. Charles JA, Souayah N. EMG/NCV in the evaluation of spine trauma with radicular symptoms. Neurol Clin Pract 2013;3:8-13.

2. American Association of Electrodiagnostic Medicine, American Academy of Physical Medicine and Rehabilitation. Practice parameter for needle electromyographic evaluation of patients with suspected cervical radiculopathy: summary statement. Muscle Nerve 1999;22:S209-S211.

3. Cho SC, Ferrante MA, Levin KH, Harmon RL, So YT. Utility of electrodiagnostic testing in evaluating patients with lumbosacral radiculopathy: an evidence-based review. Muscle Nerve 2010;42:276-282.

4. Haig AJ, Tong HC, Yamakawa KS, et al. The sensitivity and specificity of electrodiagnostic testing for the clinical syndrome of lumbar spinal stenosis. Spine 2005;30:2667-2676.

5. Wilbourn AJ. What can AAEM members do about fraud? American Association of Electrodiagnostic Medicine. Muscle Nerve 2001;24:1252.

\section{Contraindications to intravenous rtPA for acute stroke: A critical reappraisal}

Damon Fellman, MD, Hackensack University Medical Center, Hackensack, NJ: Drs. Fugate and Rabinstein ${ }^{1}$ present a compelling discussion regarding the limitations of tissue plasminogen activator (tPA) use in the current guidelines, providing evidence that favors expanding the criteria to include patients now outside the guidelines. There is also a need to examine critically whether the guidelines include patients for whom there remains insufficient evidence 
to support use of tPA, specifically the young adult age group. The guidelines appear to recommend use in the 18 to 29 age group based chiefly upon the age criteria for inclusion in the NIH 1995 tPA study. A report by Kissela et al. ${ }^{2}$ relates that young adults aged 20 to 44 are $4.1 \%$ of the stroke population. Using the figure as a rough guide, the NIH study of 333 patients is likely to involve 13 patients age 20 to 44 . The number of patients is too small to be conclusive. There is reason to believe that patients aged 18 to 29 cannot be considered similar to older patients until the issue has been studied further. The causes of stroke are different if we consider patients under age 30. One estimate suggests that illicit drug use accounts for more than $10 \%$ of stroke in young adults. There is the lower incidence of hypertension, diabetes, atherosclerotic vascular disease, and atrial fibrillation. Portions of the brain have not fully matured until the mid-20s. The pace of recovery from stroke may be different in younger adults, with improvement continuing over a much more extended time than with older patients. The American Heart Association 2011 guidelines on treatment of stroke in children ${ }^{3}$ do not recommend the use of tPA. Should patients aged 18 to 29 be considered similar to children or to older adults? And, if we are not sure, should tPA be employed in this age group based on very small numbers of treated patients? From the Child Neurology Society Ad Hoc Committee on Recognition and Treatment of Stroke in Children, ${ }^{4}$ "we cannot recommend tPA except in the setting of a controlled clinical trial." It would seem appropriate for the Food and Drug Administration to revisit the use of tPA for stroke for patients in their teens or 20s.

Disclosures: The author reports no disclosures.

Correspondence to: dfellman56@hotmail.com

Authors Respond: Jennifer E. Fugate, DO, Alejandro A. Rabinstein, MD, Mayo Clinic, Rochester, Minnesota: We thank Dr. Fellman for his comments and his interest in our article. ${ }^{1}$ While the cumulative evidence from large clinical trials and observational studies in the community overwhelmingly supports IV thrombolysis as a benefit to many patients with acute ischemic stroke, ${ }^{5,6}$ we agree that there are subgroups of patients who may deserve closer scrutiny. Dr. Fellman questions whether younger acute stroke patients (ages 18-30) should receive IV recombinant $\mathrm{PAA}$ (rtPA) given that the distribution of stroke mechanisms is different among younger adults compared to the older population. One of the larger studies on this topic compared 3,246 patients aged 18 to 50 years, who were treated with IV rtPA, to 24,425 older patients (51 to 80 years) from the Safe Implementation of Thrombolysis in Stroke-International Stroke Thrombolysis Registry. ${ }^{7}$ Although the median age was 45 years, there were 234 patients $\leq 30$ years old included in the younger group. The rate of symptomatic intracerebral hemorrhage (sICH) in patients $\leq 30$ years old was $<2 \%$ by European Cooperative Acute Stroke Study II criteria. Furthermore, younger patients had significantly higher rates of functional independence ( $72 \%$ vs $55 \%)$ and significantly lower rates of 3-month morality (5\% vs 14\%) than their older counterparts. Approximately one-third of the younger patients had stroke of "other" etiologies apart from one of the more traditional subgroups of cardioembolism, large-vessel steno-occlusive disease, or lacunar infarction. Despite this, rates of sICH and rates of good clinical outcome in patients with other etiologies were comparable to those in the more traditional stroke subtypes. Although the extent to which the good outcome in young patients depends on IV rtPA or is instead attributable to the plasticity of a younger brain is not known with certainty, this large retrospective study of a prospective database showed that IV rtPA can be safely administered to younger adults with acute ischemic stroke.

Disclosures: J. Fugate was a member of the Neurology ${ }^{\circledR}$ Resident \& Fellow Section until 2012. A. Rabinstein is on the Safety monitoring board for ALIAS and PREVAIL trials, is an Associate Editor for Neurocritical Care and on the Editorial Board for Neurology, receives publishing royalties for a book, and has received research grants from CardioNet and DJO Global.

Correspondence to: Fugate.Jennifer@mayo.edu

1. Fugate JE, Rabinstein AA. Contraindications to intravenous rtPA for acute stroke: a critical reappraisal. Neurol Clin Pract 2013;3:177-185. 
2. Kissela BM, Khoury JC, Alwell K, et al. Age at stroke: temporal trends in stroke incidence in a large, biracial population. Neurology 2012;79:1781-1787.

3. Roach ES, Golomb MR, Adams R, et al. Management of stroke in infants and children: a scientific statement from a special writing Group of the American Heart Association Stroke Council and the Council on Cardiovascular Disease in the Young. Stroke 2008;39:2644-2691.

4. Child Neurology Ad Hoc Committee on Treatment of Stroke in Children. Recognition and Treatment of Stroke in Children. Updated May 17, 2011. Available at: http://www.ninds.nih.gov/news_and_ events/proceedings/stroke_proceedings/childneurology.htm. Accessed August 1, 2013.

5. NINDS rt-PA Stroke Study Group. Tissue plasminogen activator for acute ischemic stroke: the National Institute of Neurological Disorders and Stroke rt-PA Stroke Study Group. N Eng J Med 1995;333:1581-1587.

6. Wahlgren N, Ahmed N, Davalos A, et al. Thrombolysis with alteplase for acute ischaemic stroke in the Safe Implementation of Thrombolysis in Stroke-Monitoring Study (SITS-MOST): an observational study. Lancet 2007;369:275-282.

7. Toni D, Ahmed N, Anzini A, et al; for the SITS investigators. Intravenous thrombolysis in young stroke patients: results from the SITS-ISTR. Neurology 2012;78:880-887.

\section{Early diagnosis and treatment of obstructive sleep apnea after stroke: Are we neglecting a modifiable stroke risk factor?}

Nitin K. Sethi, MD, New York-Presbyterian Hospital: Davis et al. ${ }^{1}$ highlight the importance of timely identification of sleep-disordered breathing in patients who have had an acute stroke. In the immediate aftermath of a stroke, patients are frequently obtunded and so it is not unusual for symptoms of sleep-disordered breathing such as snoring, gasping, and choking sensation while asleep and excessive daytime sleepiness to be erroneously attributed to the stroke itself. While obstructive sleep apnea is the most common, central and mixed sleep apnea should be kept in mind especially in patients who have a bulbar stroke. Another unresolved issue is the appropriate time after a stroke when sleep apnea should be diagnosed and treated; the grade of sleep-disordered breathing may spontaneously improve and continuous positive airway pressure (CPAP) requirements decrease as the stroke becomes subacute and finally chronic. Repeating the sleep study and, if warranted, retitrating the CPAP a few months after the stroke is prudent.

Disclosures N. Sethi serves as Associate Editor for The Eastern Journal of Medicine.

Correspondence to: sethinitinmd@hotmail.com

Maria Luisa Sacchetti, MD, PhD, Sapienza University, Rome: I read with interest the article by Davis et al. ${ }^{1}$ on early diagnosis and treatment of obstructive sleep apnea (OSA) after stroke. In the article, the authors exhaustively argue the negative prognostic role of OSA on stroke clinical outcome and on its recurrence, as well as evidence of the positive effect of CPAP on patients' outcome. The reasons for patients' adherence to CPAP treatment were oversimplified. The authors neglected that some pathophysiologic mechanisms responsible for sleep-disordered breathing, such as a high loop gain, can be responsible for patients' unresponsiveness to CPAP. ${ }^{2}$ In fact, a central sleep apnea-hypopnea can be detected in cases with OSA-hypopnea when treated with CPAP. ${ }^{3}$ This phenomenon has been reported to occur in stroke patients, and can verify spontaneously in patients with congestive heart failure. ${ }^{4}$ Since CPAP treatment of stroke cases has given inconclusive results, the question arises whether clinical or diagnostic parameters, or both, are able to predict unresponsive cases; a high loop gain has been proposed as one of those parameters. A schematic representation of proposed responsible mechanisms is reported in the figure.

Disclosures The author reports no disclosures.

Correspondence to: marialuisa.sacchetti@uniroma1.it

Authors Respond: Arielle P. Davis, MD, Martha E. Billings, MD, W.T. Longstreth, Jr, MD, Sandeep P. Khot, MD, Harborview Medical Center, University of Washington, Seattle: We appreciate the responses and agree that sleep-disordered breathing is common after 
Figure Obstructive sleep apnea and stroke: A schematic representation of proposed responsible mechanisms

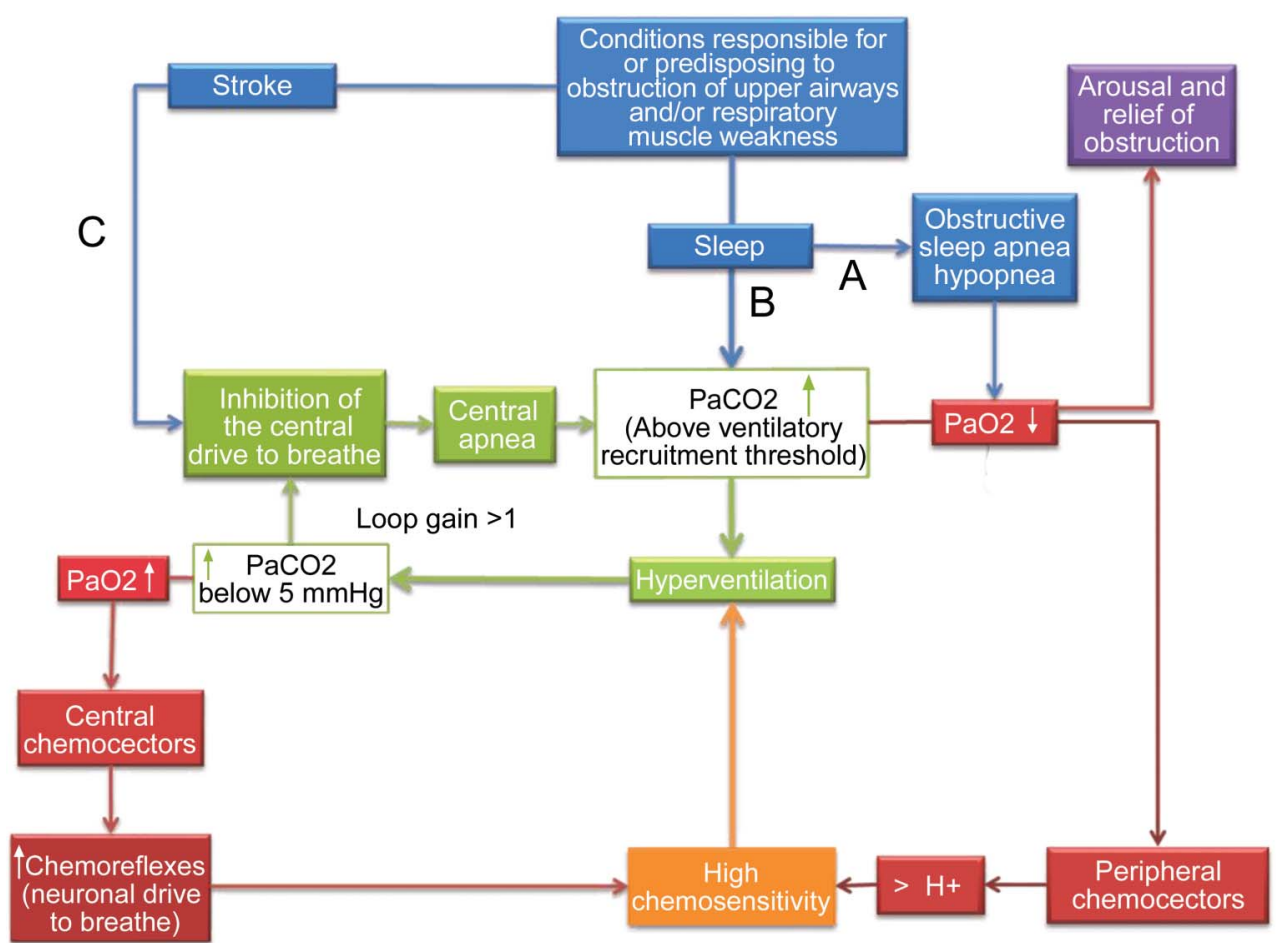

(A) Obstructive sleep apnea-hypopnea (OSAH) can precede stroke, or be caused by the effect of stroke on upper airways' caliber; the apnea is generally terminated by arousal from sleep and consequent dilation of upper airways muscles. (B) In some instances the $\mathrm{PaCO}_{2}$ can rise above the ventilatory recruitment threshold, giving origin to a loop gain >1; elevated levels of $\mathrm{PaCO}_{2}$ can be also detected in stroke patients in concomitance with either metabolic or mechanical disturbances, such as weakness of respiratory muscles. In the case of $\mathrm{PacO}_{2}$ levels above the ventilatory recruitment threshold, the physiologic loop gain equal to 1 can be altered, with the consequent alternating presence of OSAH and central sleep apnea-hypopnea (CSAH); an altered loop gain can result also from high chemosensitivity, either primary or induced by chemical stimuli consequent to $\mathrm{PaO}_{2}$ alterations (drawn respectively in orange and in red). (C) CSAH can be the direct consequence of damage to the central neuronal drive to breathe.

stroke and often not just simple OSA. In one series of 147 patients admitted to rehabilitation after a first-time stroke, $44 \%$ had a respiratory disturbance index $\geq 10$, with problems mainly due to obstructive or predominately obstructive events vs predominately central in only $6.1 \% .{ }^{5}$ Another study of patients with a first-ever stroke (73\%) or transient ischemic attack (24\%) found that in the first 48 to 72 hours after admission, $72 \%$ of patients had an apnea-hypopnea index $>10$, with $52.2 \%$ having predominantly obstructive events and $38.5 \%$ with predominantly central. ${ }^{6}$ As Dr. Sethi notes, the best time after stroke to diagnose and treat sleep apnea remains uncertain. Patient adherence to CPAP is highest when patients are treated early and while still on inpatient rehabilitation. ${ }^{7}$ While sleep-disordered breathing may improve spontaneously poststroke, OSA usually persists. In the study noted above, sleep studies repeated after 3 months showed substantial reductions in the central apnea index (6.2 to 3.3) when compared to the acute phase, but the obstructive apnea index was unchanged. ${ }^{6}$ Thus, repeating sleep studies and retitrating CPAP in the chronic phases poststroke may be justified. Dr. Sacchetti's letter accurately highlights that CPAP adherence in some cases can be related to pathophysiologic mechanisms such as high loop gain, which effectively leads to excessive ventilatory response to changes in $\mathrm{PCO}_{2} .{ }^{8}$ High loop gain may result in development of significant central apneas with the application of CPAP in $3 \%$ to $20 \%$ of patients with OSA, termed complex sleep apnea or CPAP-emergent central sleep apnea., ${ }^{9}, 10$ While the majority of these central apneas resolve after months of continued therapy, in a minority of patients, $1.5 \%$ in one of the largest studies, ${ }^{9}$ they persist and contribute to intolerance and ineffectiveness of CPAP 
therapy. It remains difficult to predict which patients have a high loop gain phenotype and are at the highest risk for developing complex sleep apnea refractory to CPAP. While stroke is a known risk factor for central sleep apnea, whether stroke is also a risk factor for high loop gain is unknown. Thus, although complex sleep apnea may limit adherence, whether stroke is associated with an increased risk of this phenomena requires further study.

Disclosures: A. Davis was involved with a commercially sponsored clinical trial: PARTNER II Trial ("Placement of Aortic Transcatheter Valves Trial”) sponsored by Edwards Lifesciences. M. Billings has received a post-MD HSRD Fellowship from the Department of Veterans Affairs, Office of Research and Development, Health Services Research \& Development. W.T. Longstreth, Jr., is a coinvestigator on several NIH-funded studies. S. Khot serves on the editorial board of Neurohospitalist and as a Section Editor of Clinical Pathological Conferences and Clinical Problem Solving.

Correspondence to: apd77@uw.edu

1. Davis AP, Billings ME, Longstreth WT, Khot SP. Early diagnosis and treatment of obstructive sleep apnea after stroke: are we neglecting a modifiable stroke risk factor? Neurol Clin Pract 2013;3:192-201.

2. Thomas RJ, Terzano MG, Parrino L, Weiss JW. Obstructive sleep-disordered breathing with a dominant cyclic alternating pattern: a recognizable polysomnographic variant with practical clinical implications. Sleep 2004;27:229-234.

3. Morgenthaler TI, Kagramanov V, Hanak V, Decker PA. Complex sleep apnea syndrome: is it a unique clinical syndrome? Sleep 2006;29:1203-1209.

4. De Paolis F, Milioli G, Grassi A, Riccardi S, Parrino L, Terzano MG. Acute shift of a case of moderate obstructive sleep apnea syndrome towards one of severe central sleep apnea syndrome after an ischemic stroke. Sleep Med 2012:763-766.

5. Wessendorf TE, Teschler H, Wang YM, Konietzko N, Thilmann AF. Sleep-disordered breathing among patients with first-ever stroke. J Neurol 2000;247:41-47.

6. Parra O, Arboix A, Bechich S, et al. Time course of sleep-related breathing disorders in first-ever stroke or transient ischemic attack. Am J Respir Crit Care Med 2000;161:375-380.

7. Ryan CM, Bayley M, Green R, Murray BJ, Bradley TD. Influence of continuous positive airway pressure on outcomes of rehabilitation in stroke patients with obstructive sleep apnea. Stroke 2011;42:1062-1067.

8. Hudgel DW, Gordon EA, Thanakitcharu S, Bruce EN. Instability of ventilator control in patients with obstructive sleep apnea. Am J Respir Crit Care Med 1998;158:1142-1149.

9. Javaheri S, Smith J, Chung E. The prevalence and natural history of complex sleep apnea. J Clin Sleep Med 2009;5:205-211.

10. Dernaika T, Tawk M, Nazir S, Younis W, Kinasewitz GT. The significance and outcome of continuous positive airway pressure-related central sleep apnea during split-night sleep studies. Chest 2007;132:81-87.

\section{ERRATUM}

Contraindications to intravenous rtPA for acute stroke: A critical reappraisal

In the article "Contraindications to intravenous rtPA for acute stroke: A critical reappraisal” by A. A. Rabinstein and J.E. Fugate (Neurol Clin Pract 2013;3:177-185), clarification is needed in the summary/introduction. The statistic that $1 \%-5 \%$ of stroke patients are treated with rtPA uses the total of all admitted Medicare patients as the denominator, regardless of the time-to-presentation. ${ }^{1,2}$ In stroke centers that report data to large registries, the more accurate statistic is closer to $20 \%{ }^{3}$ The authors regret any confusion.

1. Kleindorfer D, de los Rios La Rosa F, Khatri P, et al. Temporal trends in acute stroke management. Stroke 2013;44(6 suppl 1):S129-S131.

2. Nasr DM, Brinjikji W, Cloft HJ, et al. Utilization of intravenous thrombolysis is increasing in the United States. Int J Stroke Epub 2012 Aug 9.

3. De Los Rios la Rosa F, Khoury J, Kissela BM, et al. Eligibility for Intravenous Recombinant Tissue-Type Plasminogen Activator Within a Population: The Effect of the European Cooperative Acute Stroke Study (ECASS) III Trial. Stroke 2012;43:1591-1595. 


\section{Neurology ${ }^{\circ}$ Clinical Practice}

EMG/NCV in the evaluation of spine trauma with radicular symptoms

Andrew J. Haig, James A. Charles, John C. Kincaid, et al.

Neurol Clin Pract 2013;3;366-367

DOI 10.1212/01.CPJ.0000434951.80668.f6

This information is current as of October 14, 2013

$\begin{array}{ll}\begin{array}{l}\text { Updated Information \& } \\ \text { Services }\end{array} & \begin{array}{l}\text { including high resolution figures, can be found at: } \\ \text { http://cp.neurology.org/content/3/5/366.full.html }\end{array} \\ \text { References } & \begin{array}{l}\text { This article cites } 5 \text { articles, } 1 \text { of which you can access for } \\ \text { http://cp.neurology.org/content/3/5/366.full.html\#\#ref-lis }-1\end{array} \\ \text { Permissions \& Licensing } & \begin{array}{l}\text { Information about reproducing this article in parts (figure } \\ \text { its entirety can be found online at: } \\ \text { http://cp.neurology.org/misc/about.xhtml\#permissions } \\ \text { Information about ordering reprints can be found online: } \\ \text { http://cp.neurology.org/misc/addir.xhtml\#reprintsus }\end{array}\end{array}$

Neurol Clin Pract is an official journal of the American Academy of Neurology. Published continuously since 2011, it is now a bimonthly with 6 issues per year. Copyright (C) 2013 American Academy of Neurology. All rights reserved. Print ISSN: 2163-0402. Online ISSN: 2163-0933.

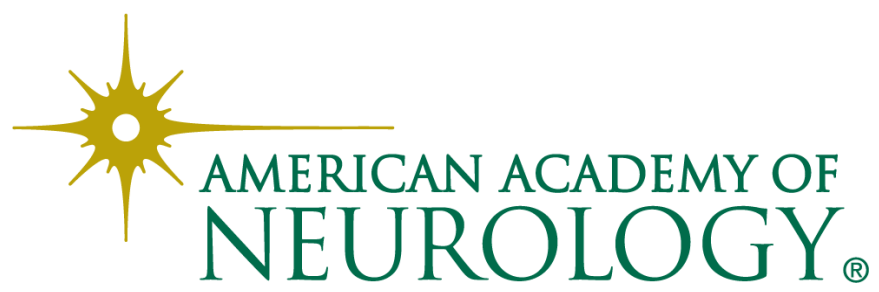

